Check for updates

Cite this: RSC Adv., 2019, 9, 17119

Received 19th March 2019

Accepted 23rd May 2019

DOI: 10.1039/c9ra02098e

rsc.li/rsc-advances

\section{The formation mechanism of uranium and thorium hydride phosphorus: a systematically theoretical study $\dagger$}

\author{
Huifeng Zhao, ${ }^{a}$ Peng Li, (DD*ac Meigang Duan, ${ }^{a}$ Feng Xie (D) ${ }^{\mathrm{b}}$ and Jie Ma ${ }^{\mathrm{ac}}$
}

Activation of prototypical bonds by actinide atoms is an important aspect of material activity, and the results can be used for the study of nuclear material storage. In this study, the activation of the $\mathrm{P}-\mathrm{H}$ bonds of the $\mathrm{PH}_{3}$ molecule by $\mathrm{U}$ or Th to form uranium or thorium hydride phosphorus has been systematically explored using density functional theory. A detailed description of the reaction mechanism which includes the potential energy profiles and the properties of bond evolution is presented. There are two types of reaction channels, isomerization and dehydrogenation in $U+\mathrm{PH}_{3}$ and $\mathrm{Th}+\mathrm{PH}_{3}$. The difference between the two reactions is the process of the first $\mathrm{P}-\mathrm{H}$ bond dissociation. The evolution characteristics of the chemical bonds along reaction pathways is analyzed by using electron localization functions, quantum theory of atoms in molecules, Mayer bond orders and natural bond orbitals. The reaction rate constants are calculated at the variational transition state level, and rate-determining steps are predicted.

\section{Introduction}

Actinides, an important component of nuclear materials, have attracted extensive attention of researchers from both the experimental and theoretical perspectives because of their unique chemical and physical properties. ${ }^{1-5}$ Since the reaction of actinides with small molecules has important applications in actinide chemistry and nuclear fuel storage, an exhaustive understanding of the reactions will contribute to the safe storage of nuclear fuel. ${ }^{6,7}$ The focus of these studies is to systematically explore the reaction mechanism, kinetics and reaction rate of activation of prototypical chemical bonds by actinide elements. In addition, the analysis of electronic structures and chemical properties of actinides is also a crucial object of these studies.

${ }^{a}$ School of Physics and Electronics Engineering, Shanxi University, Taiyuan 030006, China.E-mail: lip@sxu.edu.cn

${ }^{b}$ Institute of Nuclear and New Energy Technology, Collaborative Innovation Center of Advanced Nuclear Energy Technology, Key Laboratory of Advanced Reactor Engineering and Safety of Ministry of Education, Tsinghua University, Beijing 100084, China

${ }^{c}$ Collaborative Innovation Center of Extreme Optics, Shanxi University, Taiyuan 030006, China

$\dagger$ Electronic supplementary information (ESI) available: The comparison of observed values and calculated harmonic frequencies for $\mathrm{H}_{2} \mathrm{UPH}$ and $\mathrm{H}_{2} \mathrm{ThPH}$, comparison of the calculation results of the bond length and energy, the relative energy, the IRC curve and optimized Cartesian $x, y, z$ coordinates about the complexes and transition state for the reactants ground state from different calculation methods. Structures and selected geometric parameters of MECP and Mayer bond order analysis along the reaction pathways. See DOI: 10.1039/c9ra02098e
The experimental observations provide intuitive information for understanding such chemical reactions. ${ }^{8}$ The experiment of laser-ablated $\mathrm{Th}$ atoms and $\mathrm{NH}_{3}$ under excess argon to form thorimine $\left(\mathrm{HN}=\mathrm{ThH}_{2}\right)$ have studied, and the infrared spectrum of products were detected. ${ }^{9}$ Very recently, analogous experiment to $\mathrm{PH}_{3}$ reacting with $\mathrm{U}$ and Th atoms using laser ablated in excess argon were reported, and the new absorption in the intense An-H stretching region was discovered. ${ }^{10}$ Therefore, the current understanding of the microstructure evolution for $\mathrm{U}$, Th $+\mathrm{PH}_{3}$ reactions is not comprehensive.

In theoretical researches, with the continuous development of computing technology and theoretical methods, quantum chemistry calculations can provide further information for understanding this type of reaction. ${ }^{11}$ The reaction of $\mathrm{CH}_{4}$ and actinides has studied at density functional theory (DFT) levels. ${ }^{12,13}$ Our team also studied the detailed reactions of An atoms and their cations reacting with $\mathrm{NH}_{3}$ and $\mathrm{H}_{2} \mathrm{O}$ molecules. ${ }^{\mathbf{1 4 1 5}}$ These studies provide inspiration for exploring the reaction mechanisms, kinetics and thermodynamics of these title reactions.

The main objective of this work is to perform a detailed study of the activation of $\mathrm{P}-\mathrm{H}$ bond in $\mathrm{PH}_{3}$ molecule by $\mathrm{U}$ and $\mathrm{Th}$ atom. Multiple analysis methods are used to explore the bond evolution, involving electron localization function (ELF), ${ }^{\mathbf{1 6}}$ quantum theory of atoms in molecules (QTAIM), ${ }^{17}$ Mayer bond $\operatorname{order}^{18}$ and natural bond orbital (NBO). ${ }^{1920}$ The reaction rate constants are calculated by using the variational transition state theory (VTST), ${ }^{21}$ and the one-dimensional tunneling effects (by Eckart $^{22}$ and Wigner ${ }^{23}$ ) was considered. 


\section{Method of calculation}

Density functional theory (DFT) computations were carried out using Gaussian 16 package. ${ }^{24}$ Fully geometry optimizations and frequency computations were completed using $\mathrm{B} 3 \mathrm{LYP},{ }^{25}$ PW91PW91 ${ }^{26}$ and B3PW91, ${ }^{27}$ along with the Stuttgart-DresdenBonn relativistic effective core potential (SDD) ${ }^{28}$ for $\mathrm{U}$ and Th atoms, and the aug-cc-pVTZ ${ }^{29}$ basis set for $\mathrm{P}$ and $\mathrm{H}$ atoms. In addition, the M06- $2 \mathrm{X}^{30}$ is used with the segmented all-electron relativistically contracted (SARC) ${ }^{31}$ basis set for the An atoms. The relativistic recontracted triple- $\xi$ basis set (def2-TZVPP) ${ }^{32}$ for light $\mathrm{P}$ and $\mathrm{H}$ atoms. The zero-order regular approximation (ZORA) $)^{33}$ method is adopted. The minimum energy crossing point (MECP) between different spin potential energy surface is determined. These calculations are carried out using the ORCA 4.0.1 (ref. 34) package. These methods have been successfully applied in similar research. ${ }^{35}$ We guarantee that located transition states have only one imaginary frequency and the intrinsic reaction coordinate (IRC) results show that the corresponding vibration direction correctly connects the reactant and product. The vibrational zero-point energy (VZPE) is considered in all relative energies, and correction factors were used in vibration frequencies to take into account the influence of anharmonic effects. ${ }^{36-38}$

Electron localization function (ELF), quantum theory of atoms in molecules (QTAIM) and Mayer bond order are carried out. These analyses are completed using Multiwfn package ${ }^{39}$ the bond character, the charge distribution and metal valence population are completed using NBO in Gaussian 16 package.

The reaction rate constants with increasing temperature are accomplished by using VTST on the basis of the B3LYP/SDD/ aug-cc-pVTZ energy with KiSThelP program. ${ }^{40}$

\section{Result and discussion}

In order to estimate the accuracy of methods and basis sets, we compared the calculated vibrational frequencies of the $\mathrm{H}_{2} \mathrm{UPH}$ and $\mathrm{H}_{2} \mathrm{ThPH}$ with the experimental values. Different levels and types of methods and basis sets are chosen, the results are shown in Tables S1 and S2. $\dagger$ In addition, we summarize the bond lengths and energy of $\mathrm{H}_{2} \mathrm{UPH}$ and $\mathrm{H}_{2} \mathrm{ThPH}$ and Andrews and coworkers' calculated values. The results are listed in ESI. $\dagger$ As can be seen that B3LYP results $\left(1495.5 \mathrm{~cm}^{-1}\right.$ and $1472.6 \mathrm{~cm}^{-1}$ ) are the closest to the experimental values (1473.7 $\mathrm{cm}^{-1}$ and $1456.5 \mathrm{~cm}^{-1}$ ), followed by B3PW91 (1508.6 $\mathrm{cm}^{-1}$ and $\left.1482.9 \mathrm{~cm}^{-1}\right)$, PW91PW91 $\left(1518.3 \mathrm{~cm}^{-1}\right.$ and $\left.1493.0 \mathrm{~cm}^{-1}\right)$, and M06-2X (1526.3 $\mathrm{cm}^{-1}$ and $\left.1473.0 \mathrm{~cm}^{-1}\right)$. In terms of the basis set, SDD/aug-cc-pVTZ performs better. The comparison of bond length and energy shows that our calculations are in good agreement with Andrews. Besides, these methods have been successfully used for the study of other similar reactions. ${ }^{5,7,8}$ Therefore, the subsequent calculations are accomplished by using B3LYP/SDD/aug-cc-pVTZ, PW91PW91/ SDD/aug-cc-pVTZ, B3PW91/SDD/aug-cc-pVTZ and M06-2X/ ZORA-def2-TZVPP methods.

\section{Reaction mechanism}

The reaction mechanism of $\mathbf{U}$ atom and $\mathbf{P H}_{3}$. The ground state of complexes and transition states involved in the reaction process are located at different theoretical levels and the structures are shown in Fig. 1, and coordinates and the IRC curves are listed in ESI. $\dagger$ More than one spin states were considered, since different potential energy surfaces (PES) may be crossover during the reaction. As can be seen, the geometric parameters with different theoretical levels show consistency. The potential energy surface profile of $\mathrm{U}+\mathrm{PH}_{3}$ is presented in Fig. 2. The relative energy of complexes and transition states with respect to the intermediate $\mathrm{HUPH}_{2}$ (II) is listed in Table S5. $\dagger$ We also take into account the expected value of $S^{2}$ to make sure the spin contamination is relatively small.

From the Fig. 2, we can clearly see that the lowest energy path of $\mathrm{U}+\mathrm{PH}_{3}$ along the quintet state. For the first step of the reaction, the $\mathrm{U}$ atom attracts $\mathrm{PH}_{3}$, forming a stable complex $\mathrm{U}-$ $\mathrm{PH}_{3}(\mathrm{I})$, exothermic by approximately $11.23 \mathrm{kcal} \mathrm{mol}^{-1}$. Then, the reaction needs to overcome the first transition state (TS1) with an activation barrier of $4.14 \mathrm{kcal} \mathrm{mol}^{-1}$. The TS1 has an imaginary frequency of $398.0 \mathrm{~cm}^{-1}$, corresponding to the $\mathrm{H} 1$ atom close to the $\mathrm{U}$ atom, and the $\mathrm{P}-\mathrm{H} 1$ bond length is elongated by about $0.070 \AA$ A. After crossed TS1, the system reaches the intermediate $\mathrm{HU}-\mathrm{PH}_{2}$ (II). In this process, the $\mathrm{P}-\mathrm{H} 1$ bond is completely broken and replaced by the U-H1 bond.

After the complex II, the reaction will proceed along two different pathways, isomerization and dehydrogenation. For isomerization channel, there is an intersystem crossing between the triplet and quintet PESs, after that the reaction will proceed along triplet. In this process, the second $\mathrm{H}$ atom will move toward the $\mathrm{U}$, forming the non-planar isomerized products, the uranium dihydride phosphinidine $\mathrm{H}_{2} \mathrm{U}-\mathrm{PH}$ (III). This process overcomes the energy barrier of $16.04 \mathrm{kcal} \mathrm{mol}^{-1}$, the corresponding transition state is TS2a with a $745.3 \mathrm{~cm}^{-1}$ imaginary frequency, corresponding to the $\mathrm{H} 2$ atom from the $\mathrm{P}$ atom to the $\mathrm{U}$ atom, and the whole reaction is endothermic.

The intersystem crossing is significant for the study of the reaction process, since it characterizes where the transition is most likely to take place. ${ }^{41}$ As mentioned above, there is a crossing between triplet and quintet states in the region from complex II to TS2a. Due to the crossing reduces the barrier of quintet, the reaction will proceed along the triplet. We can see from Fig. S3, $\uparrow$ the MECP has a nonplanar geometry and is more similar to the complex II, the U-P, U-H bond lengths are $2.587 \AA$ and $2.034 \AA$, respectively. It is noteworthy that intersystem crossing is thermodynamically favored, but it can also not happen in real experiments since the energy difference between different spin states is very small.

In the dehydrogenation channel, the second $\mathrm{H}$ atom is detached from the $\mathrm{P}$ atom and gradually approaches the first $\mathrm{H}$ forming the complex $\mathrm{H}_{2}-\mathrm{UPH}$ (IV). This process needs to climb a transition state TS2b with an activation barrier of $13.9 \mathrm{kcal} \mathrm{mol}^{-1}$, and the imaginary frequency is $829.2 \mathrm{~cm}^{-1}$. At this time, the bond length of U-H1 extended from $2.150 \AA$ to $2.425 \AA$. After that, these two $\mathrm{H}$ atoms are getting farther away from the main frame, and the last complex IV decomposes into UPH and $\mathrm{H}_{2}$. 


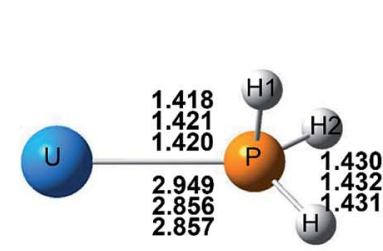

$1\left({ }^{5} \mathrm{~A}\right)$

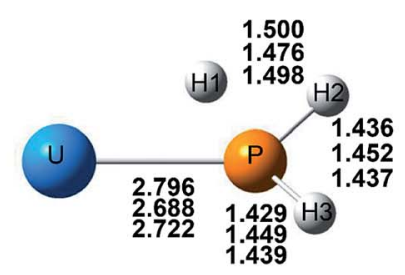

TS1 $\left({ }^{5} \mathrm{~A}\right) \mathbf{3 8 0 . 0 i}$

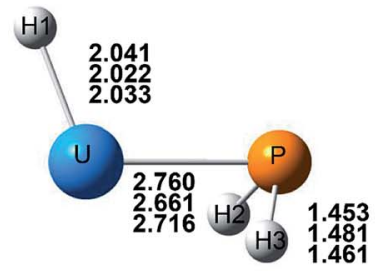

$11\left({ }^{5} A\right)$

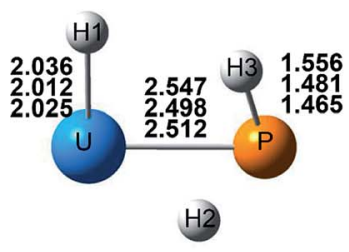

$\operatorname{TS} 2 \mathrm{a}\left({ }^{3} \mathrm{~A}\right) \mathbf{7 4 5 . 3 i}$

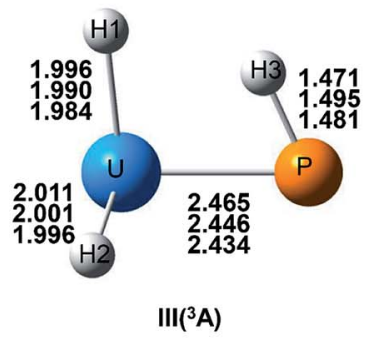

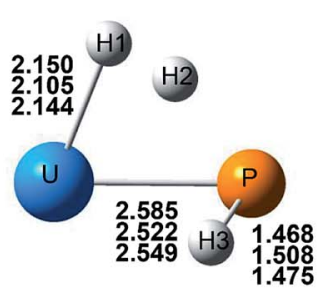

$\operatorname{TS} 2 b\left({ }^{5} A\right) 829.2 i$

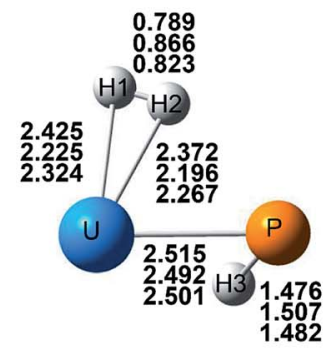

IV(5)

Fig. 1 Structures and selected geometric parameters of stationary points on the $\mathrm{U}$ and $\mathrm{PH}_{3} \mathrm{PES}$ optimized at the B3LYP/SDD/aug-cc-pVTZ, PW91/SDD/aug-cc-pVTZ, and B3PW91/SDD/aug-cc-pVTZ levels of theory (from top to bottom rows, respectively). Bond distances are $\AA$ and angles are in degree.

For the septet state, after the complex II, the subsequent reaction products are much higher than other spin multiplicity energy, and there is no crossing with other PES. We have also considered the case where $\mathrm{H}$ atoms continue to transfer from $\mathrm{P}$ atom to $\mathrm{U}$, but our results indicate that the final product is relatively higher energy, and it is very difficult to achieve in terms of energy.

The reaction mechanism of Th atom and $\mathbf{P H}_{3}$. Geometrical parameters and PES profile of the $\mathrm{Th}+\mathrm{PH}_{3}$ are presented in Fig. 3 and 4 . The relative energies of the intermediates and transition states under different theoretical calculation levels are also listed in Table S6, $\uparrow$ coordinates and the IRC curves corresponding to TS imaginary frequency are shown in ESI. $\dagger$

On the whole, the reaction mechanisms of $\mathrm{Th}+\mathrm{PH}_{3}$ are very similar to that of $\mathrm{U}+\mathrm{PH}_{3}$. It can be summarized as follows, the first step of the reaction is An atoms attracted the $\mathrm{PH}_{3}$ molecule to form complex I, then overcome TS1 and dissociate the first $\mathrm{P}-\mathrm{H}$ bond to produce intermediate II. Dissociation of the second $\mathrm{P}-\mathrm{H}$ bond has different spatial directionalities leading to two channels of isomerization and dehydrogenation.

Our results show that the difference between two reactions is the process of dissociating the first $\mathrm{P}-\mathrm{H}$ bond. In the case of $\mathrm{Th}$

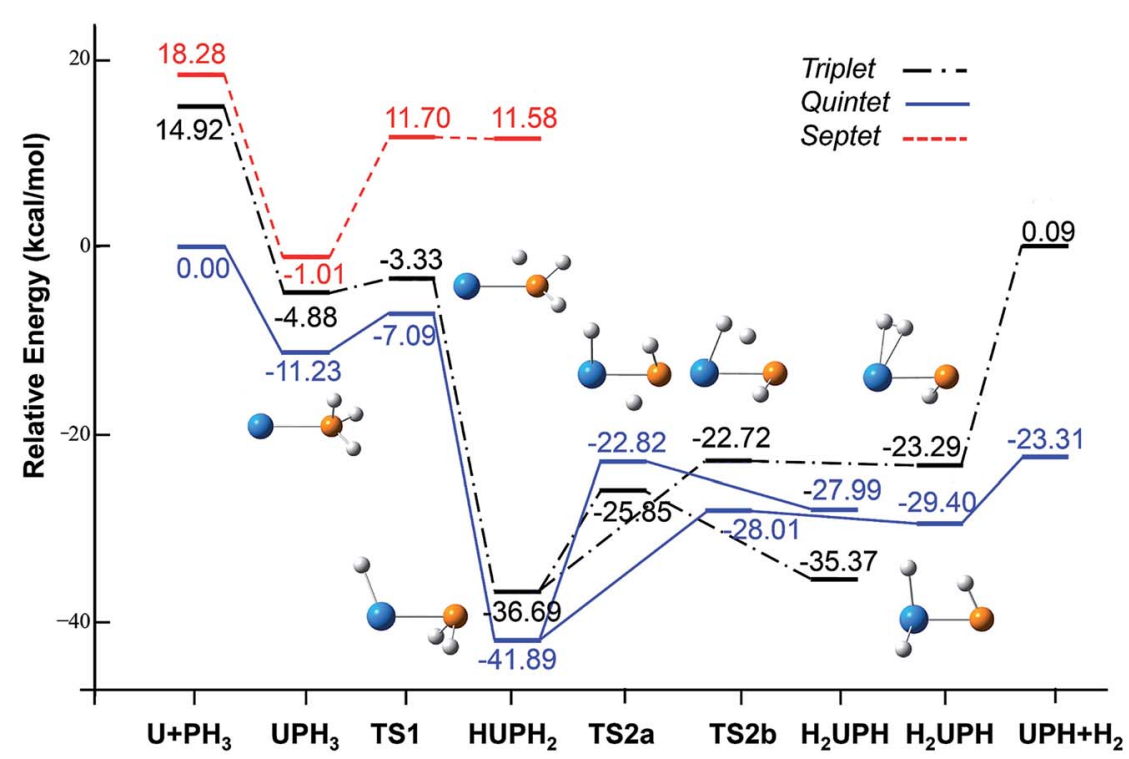

Fig. 2 Potential energy profile for the reaction of $\mathrm{U}+\mathrm{PH}_{3}$ computed at the B3LYP/SDD/aug-cc-pVTZ levels of theory. The energy in the figure is relative to the total energy of $U+\mathrm{PH}_{3}$ (quintet). 


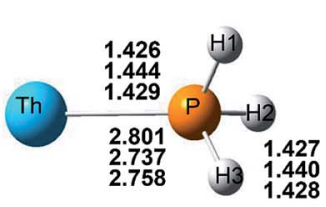

$1\left({ }^{3} \mathrm{~A}\right)$

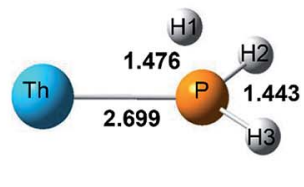

TS1'( $\left.{ }^{1} \mathrm{~A}\right) 339.8 \mathrm{i}$

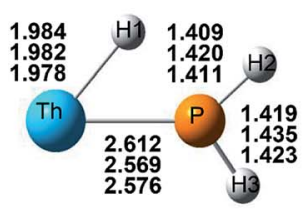

II'( $\left.{ }^{1} \mathbf{A}\right)$

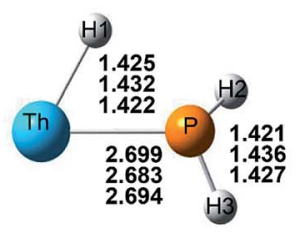

TS1( $\left.{ }^{1} \mathrm{~A}\right) 157.3 i$

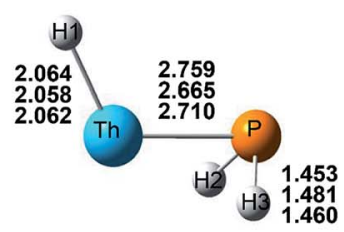

$\| 1\left({ }^{3} \mathrm{~A}\right)$

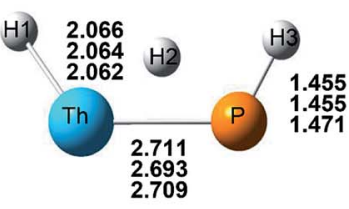

TS2a $\left({ }^{3} \mathrm{~A}\right) 863.5 i$

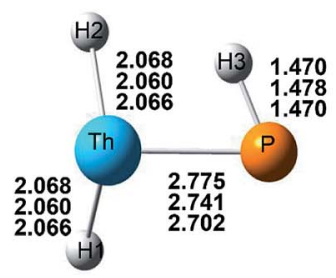

III $\left({ }^{3} \mathrm{~A}\right)$

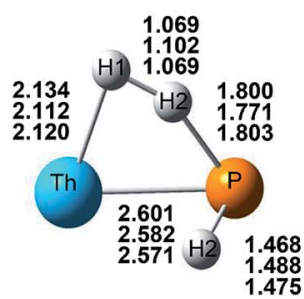

TS2b('A) $1035.1 i$

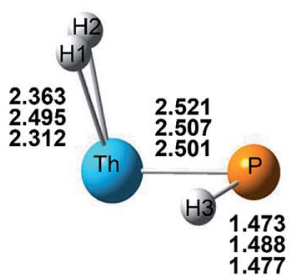

IV(' $\left.{ }^{1} \mathrm{~A}\right)$

Fig. 3 Structures and selected geometric parameters of stationary points on the Th and $\mathrm{PH}_{3} \mathrm{PES}$ optimized at the B3LYP/SDD/aug-cc-pVTZ, PW91/SDD/aug-cc-pVTZ, and B3PW91/SDD/aug-cc-pVTZ levels of theory (from top to bottom rows, respectively). Bond distances are $\AA$ and angles are in degree.

$+\mathrm{PH}_{3}$, the $\mathrm{P}-\mathrm{H} 1$ bond cleavage of singlet reaction needs two steps. There are two transition states in this process, we named TS1 $^{\prime}$ and TS1. The activation barrier of the TS1' is very shallow, only $0.06 \mathrm{kcal} \mathrm{mol}^{-1}$. The corresponding process is that the $\mathrm{P}-$ $\mathrm{H} 1$ bond is slightly elongated and forms an intermediate product II' $^{\prime}$ with a planar structure. Then the $\mathrm{H}$ atom continues to move toward the Th atom, and the molecular structure changes from plane to three-dimensional, the complex II formed. This process requires the system to pass through TS1 with a barrier height of $13.84 \mathrm{kcal} \mathrm{mol}^{-1}$, the imaginary frequency is $157.3 \mathrm{~cm}^{-1}$. Besides, for the dissociation of $\mathrm{P}-\mathrm{H} 1$ bond, the different spin multiplicity corresponds to different situations. If the reaction proceeds along the singlet state, the above two steps are required to dissociate the $\mathrm{P}-\mathrm{H} 1 \mathrm{bond}$, if along the triplet state, this process is same as $\mathrm{U}+\mathrm{PH}_{3}$, only one step is needed. It should be noted, the calculation of complex I and $\mathrm{TS1}^{\prime}$ for singlet state was successful only on B3LYP/SDD/ aug-cc-pVTZ method. We have tried other methods, but failed. This may be due to the relatively small energy barrier of TS1' and sensitive to the calculation method. From the above analysis, the reaction process of $\mathrm{U}+\mathrm{PH}_{3}$ and $\mathrm{Th}+\mathrm{PH}_{3}$ can be described as:

$$
\begin{gathered}
\mathrm{U}+\mathrm{PH}_{3} \rightarrow{\mathrm{U}-\mathrm{PH}_{3} \rightarrow \mathrm{TS} 1 \rightarrow \mathrm{HU}-\mathrm{PH}_{2} \rightarrow \mathrm{TS} 2 \mathrm{a} \rightarrow \mathrm{H}_{2} \mathrm{U}-\mathrm{PH}}_{\Delta E=-35.37 \mathrm{kcal} \mathrm{mol}^{-1}} \\
\mathrm{U}+\mathrm{PH}_{3} \rightarrow \mathrm{U}-\mathrm{PH}_{3} \rightarrow \mathrm{TS} 1 \rightarrow \mathrm{HU}-\mathrm{PH}_{2} \rightarrow \mathrm{TS}^{2} \mathrm{~b} \rightarrow \mathrm{H}_{2}-\mathrm{U}-\mathrm{PH} \\
\rightarrow \mathrm{H}_{2}+\mathrm{UPH}, \Delta E=-23.31 \mathrm{kcal} \mathrm{mol}^{-1}
\end{gathered}
$$

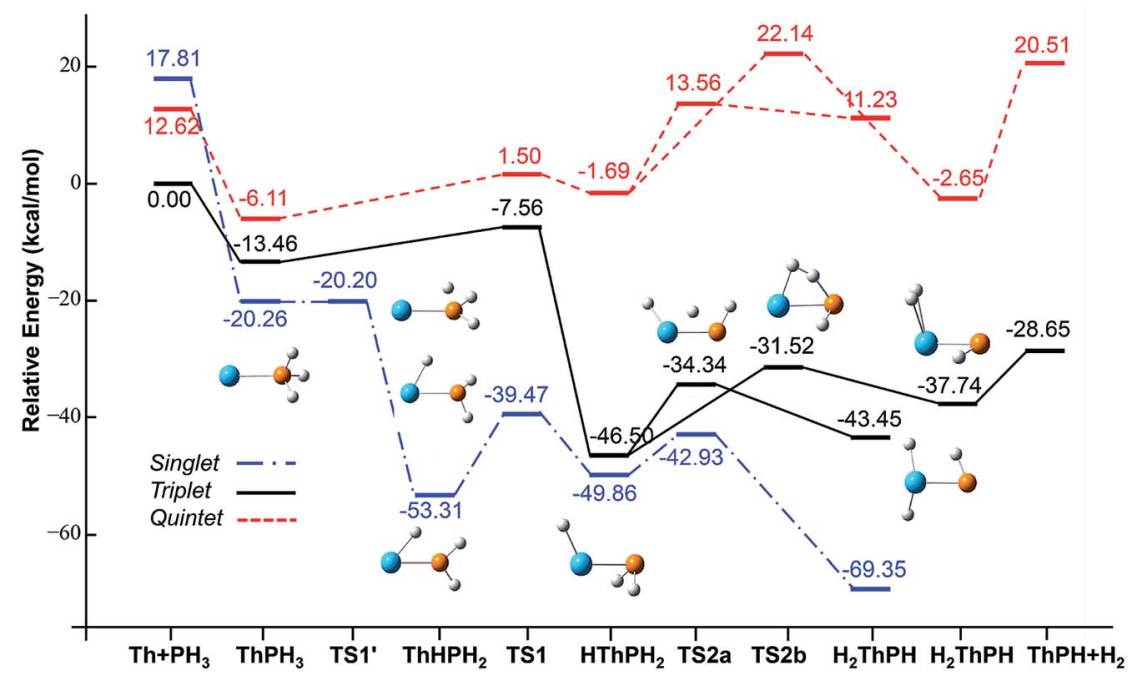

Fig. 4 Potential energy profile for the reaction of $\mathrm{Th}+\mathrm{PH}_{3}$ computed at the B3LYP/SDD/aug-cc-pVTZ levels of theory. The energy in the figure is relative to the total energy of $\mathrm{Th}+\mathrm{PH}_{3}$ (triplet). 


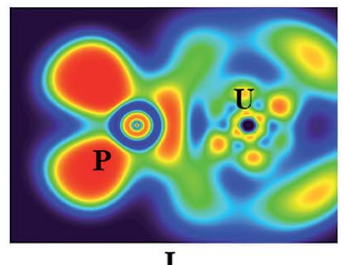

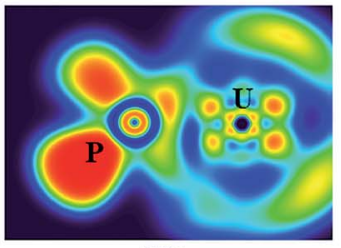

TS1

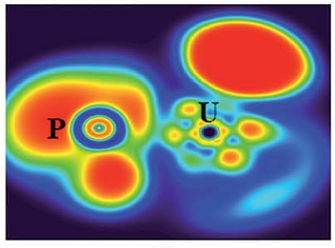

II

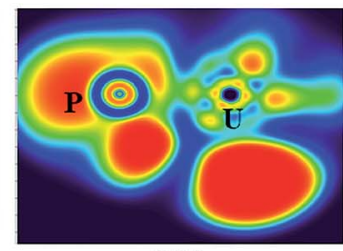

TS2a

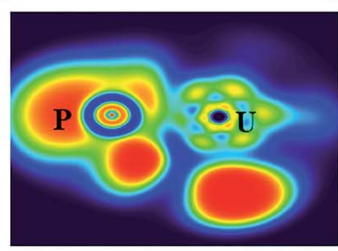

III

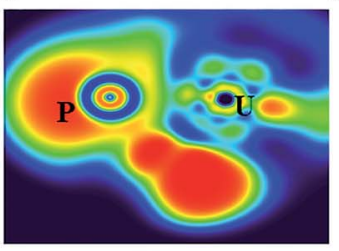

TS2b

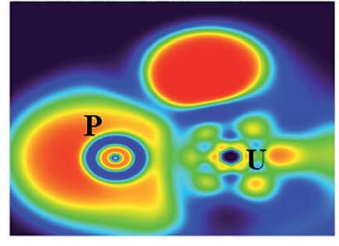

IV

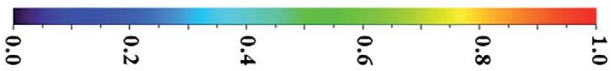

Fig. 5 ELF shaded surfaces with projection maps of the stationary points on the $U+\mathrm{PH}_{3}$ reaction pathway at the B3LYP/SDD/aug-cc-pVTZ level theory.

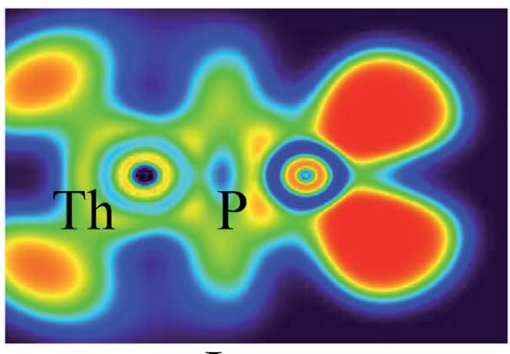

I

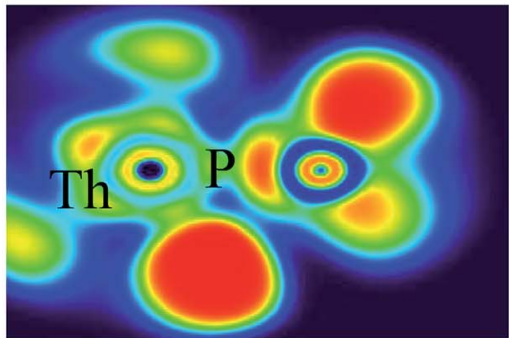

TS1

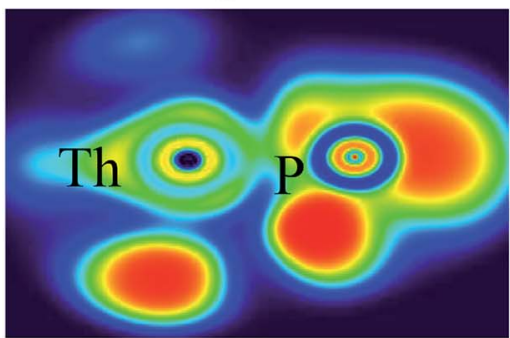

III

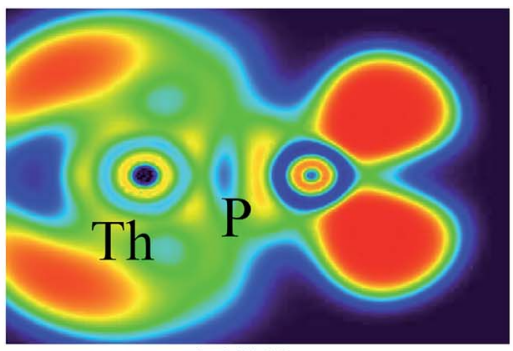

TS1

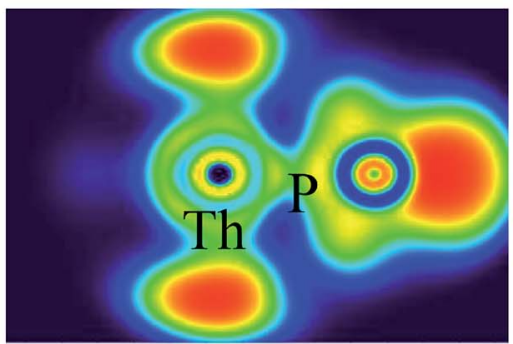

II

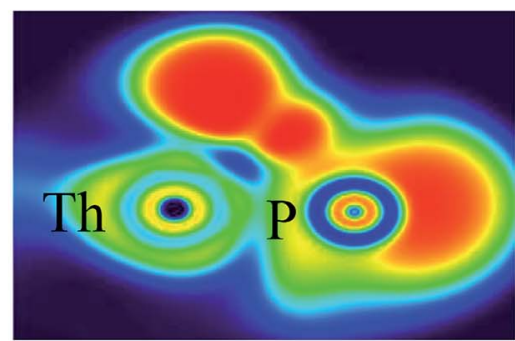

TS2b

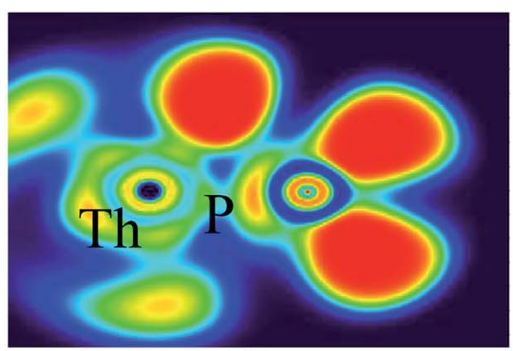

II'

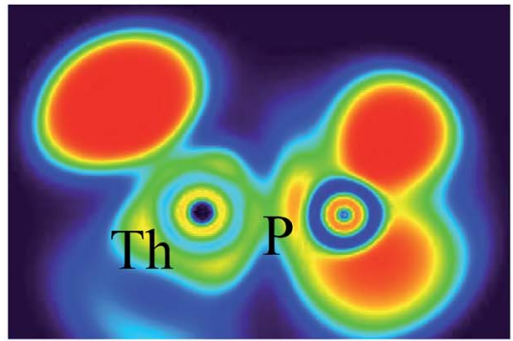

TS2a

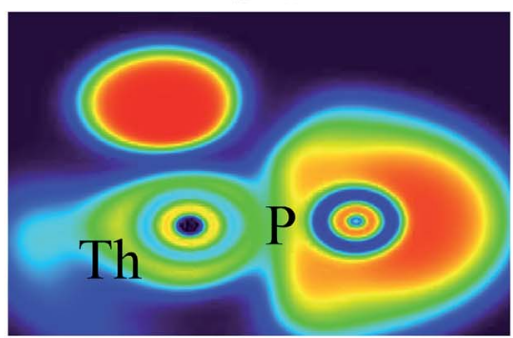

IV

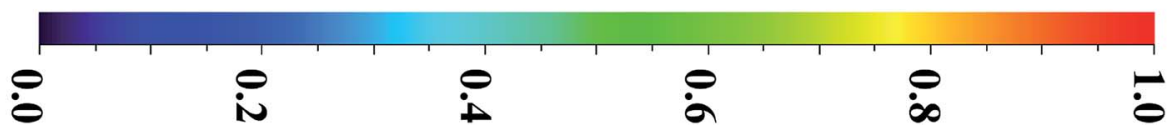

Fig. 6 ELF shaded surfaces with projection maps of the stationary points on the $\mathrm{Th}+\mathrm{PH}_{3}$ reaction pathway at the B3LYP/SDD/aug-cc-pVTZ level theory. 


$$
\begin{gathered}
\mathrm{Th}+\mathrm{PH}_{3} \rightarrow \mathrm{Th}-\mathrm{PH}_{3} \rightarrow \mathrm{TS}^{\prime} \rightarrow \mathrm{Th}-\mathrm{H}-\mathrm{PH}_{2} \rightarrow \mathrm{TS} 1 \rightarrow \mathrm{HTh}- \\
\mathrm{PH}_{2} \rightarrow \mathrm{TS} 2 \mathrm{a} \rightarrow \mathrm{H}_{2} \mathrm{Th}-\mathrm{PH}, \Delta E=-81.36 \mathrm{kcal} \mathrm{mol}^{-1}
\end{gathered}
$$$$
\mathrm{Th}+\mathrm{PH}_{3} \rightarrow \mathrm{Th}-\mathrm{PH}_{3} \rightarrow \mathrm{TS} 1 \rightarrow \mathrm{HTh}-\mathrm{PH}_{2} \rightarrow \mathrm{TS} 2 \mathrm{~b} \rightarrow \mathrm{H}_{2}-\mathrm{Th}-
$$$$
\mathrm{PH} \rightarrow \mathrm{H}_{2}+\mathrm{ThPH}, \Delta E=-28.65 \mathrm{kcal} \mathrm{mol}^{-1}
$$

Topological analysis. In order to obtain the detailed characteristic of the bonding evolution along the reaction pathway, different analysis methods such as ELF, QTAIM, Mayer bond order and NBO analysis are employed. Analysis of ELF and QTAIM qualitatively discusses the bonding properties. For a more comprehensive analysis, Mayer bond order quantitatively analyzes the formation and fracture of chemical bonds, and the result is listed in ESI. $\dagger$

The ELF shaded-surface-projected maps of complexes and transition states (lowest-energy spin state species) for $\mathrm{U}+\mathrm{PH}_{3}$ and $\mathrm{Th}+\mathrm{PH}_{3}$ are shown in Fig. 5 and 6. The QTAIM parameters of the $(3,-1)$ bond critical points (BCPs) for the species involved in the reactions are gathered in Table $1\left(\mathrm{U}+\mathrm{PH}_{3}\right)$ and Table $\mathrm{S} 9 \dagger$ $\left(\mathrm{Th}+\mathrm{PH}_{3}\right)$, including the electron density $\rho(r)$ and Laplacian $\nabla^{2} \rho(r)$, the potential energy density $V(r)$, the electron kinetic energy density $G(r)$ and the total electron energy density $H(r)$. As the criteria proposed by Cremer and Kraka, ${ }^{\mathbf{4 2}} H(r)>0$ corresponds to closed-shell interactions, and $H(r)<0$ corresponds to covalent interactions.

Table 1 Topological properties of the charge density calculated at the $(3,-1)$ BCPs for all species involved in the reaction of $U+\mathrm{PH}_{3}$ at the

\begin{tabular}{|c|c|c|c|c|c|c|}
\hline & Species & $\rho(r)$ & $\nabla^{2} \rho(r)$ & $G(r)$ & $V(r)$ & $H(r)$ \\
\hline \multirow[t]{4}{*}{$\mathrm{I}\left({ }^{5} \mathrm{~A}\right)$} & $\mathrm{U}-\mathrm{P}$ & 0.042 & 0.094 & 0.030 & -0.037 & -0.684 \\
\hline & $\mathrm{P}-\mathrm{H} 1$ & 0.165 & -0.114 & 0.137 & -0.302 & -0.165 \\
\hline & $\mathrm{P}-\mathrm{H} 2$ & 0.163 & -0.161 & 0.124 & -0.288 & -0.164 \\
\hline & $\mathrm{P}-\mathrm{H} 3$ & 0.164 & -0.160 & 0.124 & -0.289 & -0.164 \\
\hline \multirow[t]{4}{*}{$\mathrm{TS} 1\left({ }^{5} \mathrm{~A}\right)$} & $\mathrm{U}-\mathrm{P}$ & 0.052 & 0.063 & 0.029 & -0.041 & -0.013 \\
\hline & P-H1 & 0.144 & -0.271 & 0.062 & -0.192 & -0.130 \\
\hline & $\mathrm{P}-\mathrm{H} 2$ & 0.163 & -0.164 & 0.123 & -0.286 & -0.164 \\
\hline & P-H3 & 0.164 & -0.155 & 0.126 & -0.290 & -0.165 \\
\hline \multirow[t]{4}{*}{$\mathrm{II}\left({ }^{5} \mathrm{~A}\right)$} & $\mathrm{U}-\mathrm{P}$ & 0.068 & 0.028 & 0.029 & -0.050 & -0.022 \\
\hline & $\mathrm{U}-\mathrm{H} 1$ & 0.090 & 0.023 & 0.040 & -0.075 & -0.035 \\
\hline & $\mathrm{P}-\mathrm{H} 2$ & 0.147 & -0.081 & 0.117 & -0.255 & -0.137 \\
\hline & P-H3 & 0.149 & -0.067 & 0.124 & -0.264 & -0.140 \\
\hline \multirow[t]{4}{*}{$\operatorname{TS} 2 \mathrm{a}\left({ }^{3} \mathrm{~A}\right)$} & $\mathrm{U}-\mathrm{P}$ & 0.095 & 0.021 & 0.046 & -0.086 & -0.040 \\
\hline & U-H1 & 0.088 & 0.036 & 0.042 & -0.075 & -0.033 \\
\hline & $\mathrm{U}-\mathrm{H} 2$ & 0.075 & 0.062 & 0.040 & -0.064 & -0.024 \\
\hline & P-H3 & 0.147 & -0.070 & 0.119 & -0.256 & -0.137 \\
\hline \multirow[t]{4}{*}{$\operatorname{III}\left({ }^{3} \mathrm{~A}\right)$} & $\mathrm{U}-\mathrm{P}$ & 0.109 & 0.027 & 0.058 & -0.110 & -0.051 \\
\hline & U-H1 & 0.097 & 0.012 & 0.043 & -0.083 & -0.040 \\
\hline & $\mathrm{U}-\mathrm{H} 2$ & 0.097 & 0.018 & 0.045 & -0.085 & -0.040 \\
\hline & $\mathrm{P}-\mathrm{H} 3$ & 0.141 & -0.049 & 0.115 & -0.241 & -0.127 \\
\hline \multirow[t]{5}{*}{$\mathrm{TS} 2 \mathrm{~b}\left({ }^{5} \mathrm{~A}\right)$} & U-P & 0.088 & 0.034 & 0.044 & -0.079 & -0.035 \\
\hline & U-H1 & 0.063 & 0.104 & 0.041 & -0.056 & -0.015 \\
\hline & $\mathrm{U}-\mathrm{H} 2$ & 0.052 & 0.167 & 0.049 & -0.056 & -0.007 \\
\hline & $\mathrm{P}-\mathrm{H} 3$ & 0.141 & -0.065 & 0.111 & -0.238 & -0.127 \\
\hline & $\mathrm{H} 1-\mathrm{H} 2$ & 0.140 & -0.306 & 0.026 & -0.129 & -0.103 \\
\hline \multirow[t]{3}{*}{$\operatorname{IV}\left({ }^{5} \mathrm{~A}\right)$} & $\mathrm{U}-\mathrm{P}$ & 0.100 & 0.028 & 0.051 & -0.095 & -0.044 \\
\hline & $\mathrm{P}-\mathrm{H} 3$ & 0.138 & -0.063 & 0.107 & -0.229 & -0.123 \\
\hline & $\mathrm{H} 1-\mathrm{H} 2$ & 0.241 & -0.960 & 0.008 & -0.257 & -0.240 \\
\hline
\end{tabular}
B3LYP/SDD/aug-cc-pVTZ level of theory ${ }^{a}$

${ }^{a} \rho(\mathrm{bcp})$ and $\nabla^{2} \rho(\mathrm{bcp})$ in a.u.
$\mathbf{U}-\mathbf{P H}_{3}$ and $\mathbf{T h}-\mathbf{P H}_{3}$. The ELF analysis illustrates the absence of a disynaptic valence basin between the An atom and $\mathrm{P}$ atom. The QTAIM analysis explains that there is a $(3,-1)$ critical point between An and P atom, and $H(r)$ is negative. And $\rho(r)$ is very low ( 0.042 in the case of $\mathrm{U}-\mathrm{PH}_{3}, 0.065$ in the case of $\mathrm{Th}-\mathrm{PH}_{3}$ ), the $\nabla^{2} \rho(r)$ values are small and positive $\left(0.094\right.$ correspond to $\mathrm{U}-\mathrm{PH}_{3}$, 0.134 correspond to $\left.\mathrm{Th}-\mathrm{PH}_{3}\right)$. These facts indicate that there is a covalent interaction between the fragments in complex I.

TS1'. This TS exists only in the singlet state of the $\mathrm{Th}+\mathrm{PH}_{3}$ reaction. Topological analysis demonstrates that the interaction between $\mathrm{P}$ and $\mathrm{H} 1$ atom is weakening. According to the QTAIM analysis, the $\rho(r)$ of $\mathrm{P}-\mathrm{H} 1$ decreases from 0.161 to 0.156 , the $H(r)$ is negative. The value for the $\mathrm{P}-\mathrm{H} 1$ is different from the other two bonds, which mean that the $\mathrm{P}-\mathrm{H} 1$ bond changes.

Th-H-PH $\mathbf{H}_{2}$. The complex II' only present in the reaction of $\mathrm{Th}$ $+\mathrm{PH}_{3}$. The ELF analysis indicates the lack of the $\mathrm{V}(\mathrm{P}, \mathrm{H} 1)$ basin, which is replaced by the $\mathrm{V}(\mathrm{Th}, \mathrm{H} 1, \mathrm{P})$ basin. The result of QTAIM also supports this fact, the value of $\rho(r)$ for Th-H1 bond is increased (0.098), and $H(r)<0$ indicates the covalent interaction between the Th and $\mathrm{H} 1$ atom.

TS1 species. Through the above analysis, the connection process of $\mathrm{U}+\mathrm{PH}_{3}$ and $\mathrm{Th}+\mathrm{PH}_{3}$ are different at TS1, so the electronic topology parameters are distinguishing. For $\mathrm{U}+\mathrm{PH}_{3}$, topological analysis reveals that the first $\mathrm{P}-\mathrm{H} 1$ bond dissociated in this process, which is represented by the fact that $\mathrm{V}(\mathrm{P}, \mathrm{H} 1)$ is replaced by a three-synaptic basin $\mathrm{V}(\mathrm{U}, \mathrm{H} 1, \mathrm{P})$ in the ELF analysis. QTAIM analysis shows the values of $\rho$ (bcp) for P-H1 have significant decrease relative to the $\mathrm{P}-\mathrm{H} 2, H(r)<0$ demonstrates the covalent interaction between $\mathrm{P}$ atom and $\mathrm{H} 1$. For the singlet state of the reaction of $\mathrm{Th}+\mathrm{PH}_{3}$, the ELF analysis indicates the emergence of $\mathrm{V}$ (Th, H1). The QTAIM analysis also illustrates this, the charge density of Th-H1 increases from 0.098 to 0.109 . For the triplet state, the situation of $\mathrm{Th}+\mathrm{PH}_{3}$ is similar to $\mathrm{U}+\mathrm{PH}_{3}$.

$\mathbf{H U}-\mathbf{P H}_{2}$ and $\mathbf{H T h}-\mathbf{P H}_{2}$. The ELF and QTAIM analysis reveals $\mathrm{P}-\mathrm{H} 1$ bonds are completely broken, forming the An-H1 covalent bond, which evidenced by the trisynaptic V (An, H1, P) is completely replaced by a disynaptic $\mathrm{V}(\mathrm{An}, \mathrm{H} 1)$, the presence of a $(3,-1)$ BCP between the An and $\mathrm{H} 1$ atom where the $H(r)$ is negative.

Table 2 Natural bond orbital analysis for all species of the reaction of

\begin{tabular}{|c|c|c|c|c|c|c|}
\hline \multirow[b]{2}{*}{ Species } & \multirow[b]{2}{*}{ Bond character } & \multirow[b]{2}{*}{$q_{\mathrm{Th}}$} & \multirow[b]{2}{*}{$q_{\mathrm{P}}$} & \multicolumn{3}{|c|}{$\begin{array}{l}\text { Metal valence } \\
\text { populations }\end{array}$} \\
\hline & & & & $7 \mathrm{~s}$ & $5 f$ & $6 \mathrm{~d}$ \\
\hline I & $\mathrm{BD}(1)$ Occ. $=0.871$ & 0.192 & -0.169 & 1.88 & 2.62 & 0.84 \\
\hline TS1 & $\mathrm{BD}(1)$ Occ. $=0.827$ & 0.987 & -0.203 & 0.87 & 2.99 & 0.20 \\
\hline II & $\mathrm{BD}(1)$ Occ. $=0.997$ & 1.072 & -0.399 & 1.03 & 3.00 & 0.96 \\
\hline TS2a & $\begin{array}{l}\mathrm{BD}(1) \text { Occ. }=0.990 \\
\mathrm{BD}(2) \text { Occ. }=0.916\end{array}$ & 1.174 & -0.401 & 0.63 & 3.04 & 1.12 \\
\hline III & $\begin{array}{l}\mathrm{BD}(1) \text { Occ. }=0.997 \\
\mathrm{BD}(2) \text { Occ. }=0.997\end{array}$ & 1.146 & -0.422 & 0.49 & 3.06 & 1.72 \\
\hline TS2b & $\mathrm{BD}(1)$ Occ. $=0.992$ & 0.639 & -0.356 & 0.96 & 3.12 & 1.23 \\
\hline IV & $\mathrm{BD}(1)$ Occ. $=0.996$ & 0.644 & -0.467 & 0.93 & 3.16 & 1.28 \\
\hline
\end{tabular}
$\mathrm{U}+\mathrm{PH}_{3}$ calculated at the B3LYP/SDD/aug-cc-pVTZ level of theory 
Table 3 Natural bond orbital analysis for all species of the reaction of $\mathrm{Th}+\mathrm{PH}_{3}$ calculated at the B3LYP/SDD/aug-cc-pVTZ level of theory

\begin{tabular}{|c|c|c|c|c|c|c|}
\hline \multirow[b]{2}{*}{ Species } & \multirow[b]{2}{*}{ Bond character } & \multirow[b]{2}{*}{$q_{\mathrm{Th}}$} & \multirow[b]{2}{*}{$q_{\mathrm{P}}$} & \multicolumn{3}{|c|}{$\begin{array}{l}\text { Metal valence } \\
\text { populations }\end{array}$} \\
\hline & & & & $7 \mathrm{~s}$ & $5 f$ & $6 d$ \\
\hline I & $\begin{array}{l}\mathrm{BD}(1) \text { Occ. }=1.979 \\
\mathrm{BD}(2) \text { Occ. }=1.790\end{array}$ & 0.199 & -0.088 & 1.74 & 0.10 & 1.96 \\
\hline $\mathrm{TS}^{\prime}$ & $\begin{array}{l}\mathrm{BD}(1) \text { Occ. }=1.978 \\
\mathrm{BD}(2) \text { Occ. }=1.783\end{array}$ & 0.209 & -0.089 & 1.73 & 0.11 & 1.95 \\
\hline $\mathrm{II}^{\prime}$ & $\begin{array}{l}\mathrm{BD}(1) \text { Occ. }=1.999 \\
\mathrm{BD}(2) \text { Occ. }=1.961\end{array}$ & 0.729 & -0.389 & 1.67 & 0.19 & 1.40 \\
\hline TS1 & $\begin{array}{l}\mathrm{BD}(1) \text { Occ. }=1.963 \\
\mathrm{BD}(2) \text { Occ. }=1.988\end{array}$ & 0.790 & -0.417 & 1.63 & 0.17 & 1.39 \\
\hline II & $\mathrm{BD}(1)$ Occ. $=1.995$ & 0.922 & -0.309 & 1.49 & 0.21 & 1.35 \\
\hline TS2a & $\begin{array}{l}\mathrm{BD}(1) \text { Occ. }=1.944 \\
\mathrm{BD}(2) \text { Occ. }=1.943 \\
\mathrm{BD}(3) \text { Occ. }=1.759\end{array}$ & 0.984 & -0.372 & 1.00 & 0.28 & 1.74 \\
\hline III & $\begin{array}{l}\mathrm{BD}(1) \text { Occ. }=1.997 \\
\mathrm{BD}(2) \text { Occ. }=1.991 \\
\mathrm{BD}(3) \text { Occ. }=1.793\end{array}$ & 1.312 & -0.454 & 0.47 & 0.29 & 1.92 \\
\hline TS2b & $\begin{array}{l}\mathrm{BD}(1) \text { Occ. }=0.998 \\
\mathrm{BD}(2) \text { Occ. }=0.726\end{array}$ & 0.690 & -0.267 & 0.77 & 0.26 & 2.14 \\
\hline IV & $\begin{array}{l}\mathrm{BD}(1) \text { Occ. }=0.999 \\
\mathrm{BD}(2) \text { Occ. }=0.998\end{array}$ & 0.598 & -0.470 & 0.79 & 0.35 & 2.30 \\
\hline
\end{tabular}

TS2a species. This stage is the beginning of isomerization, the second $\mathrm{H}$ atom shift from $\mathrm{P}$ atom to An atom. The ELF topological analysis indicates the $\mathrm{P}-\mathrm{H} 2$ bond has not yet completely broken, the appearance of the trisynaptic V (An, H2, P) basin proves this. QTAIM analysis provides strong support for this fact, the value of $\rho(r)$ of An- $\mathrm{H} 2$ bond increases, and the $H(r)$ is negative, suggesting the covalent interaction between An atom and $\mathrm{H} 2$.

$\mathbf{H}_{2} \mathrm{U}-\mathbf{P H}$ and $\mathbf{H}_{2} \mathbf{T h}-\mathbf{P H}$. The formation of the intermediate $\mathrm{HPAnH}_{2}$ demonstrates the $\mathrm{P}-\mathrm{H} 2$ bond is completely broken. This fact is evidenced by the lack of $\mathrm{V}(\mathrm{An}, \mathrm{H} 2, \mathrm{P})$ basin, which replaced by $\mathrm{V}(\mathrm{An}, \mathrm{H} 2)$ basin. The $\rho(r)$ of the $\mathrm{An}-\mathrm{H} 2$ is gradually increased. The topological parameters of the An- $\mathrm{H} 1$ and $\mathrm{An}-\mathrm{H} 2$ bond are almost the same, this is consistent with the axisymmetric nature of the two $\mathrm{H}$ atoms with respect to the An-P bond. In addition, the $\rho(r)$ of An-P gradually increases along the reaction paths.

TS2b species. From the result of ELF, the presence of a new trisynaptic basin $\mathrm{V}(\mathrm{H} 1, \mathrm{H} 2, \mathrm{P})$ indicates the second $\mathrm{P}-\mathrm{H}$ bond begins to break and two $\mathrm{H}$ atom approach each other during this process. The QTAIM analysis shows that the $\rho(r)$ of $\mathrm{H} 1-\mathrm{H} 2$ significantly increases. The $H(r)$ of $\mathrm{H} 1-\mathrm{H} 2$ is negative. In addition, the value of $\rho(r)$ between An and $\mathrm{H} 1-\mathrm{H} 2$ is reduced, which implies that two $\mathrm{H}$ atoms are gradually detaching from the An atom.

$\mathbf{H}_{2}-\mathbf{U}-\mathbf{P H}$ and $\mathbf{H}_{2}-\mathbf{T h}-\mathbf{P H}$. The disappearance of two disynaptic valence basin $\mathrm{V}(\mathrm{An}, \mathrm{H} 1)$ and $\mathrm{V}(\mathrm{P}, \mathrm{H} 2)$, leading to the appearance of a disynaptic $\mathrm{V}(\mathrm{H} 1, \mathrm{H} 2)$, and the value of $\rho(r)$ increases obviously at the $\mathrm{H} 1-\mathrm{H} 2 \mathrm{BCP}$ and the corresponding $H(r)$ is negative.

NBO analysis. The bond character, natural population analysis (NPA) atom charges and the corresponding metal valence population of the intermediate and transition state along the reaction pathways are listed in Tables 2 and 3. As can be seen from table, the NPA charge of $U$ and $T h$ atom is positive and increases as the reaction progresses, the NPA charge of P atom becomes more negative along the reaction pathways. The metal valence populations also provide more information about the $5 \mathrm{f}$-character. The population of $5 \mathrm{f}$ orbitals increase from 2.62 to 3.06 for the reaction of $\mathrm{U}$ and $\mathrm{PH}_{3}$ (from 0.10 to 0.29 for $\mathrm{Th}+\mathrm{PH}_{3}$ ). Besides, it can be seen that there is direct involvement of the $5 \mathrm{f}$ orbital in the products.

We calculated the electronic occupancy in order to investigate the multiple bonds between An and P atoms. As can be seen, on the whole, the An-P bond in Th species exhibit more multiple bond properties than in $\mathrm{U}$ species. For $\mathrm{U}+\mathrm{PH}_{3}$, each $\mathrm{BD}$ has only one electron, the An-P bonds in all the species are partial multiple bonds that are not completely occupied. For Th $+\mathrm{PH}_{3}$, each $\mathrm{BD}$ have two electronic occupations, except for $\mathrm{H}_{2}-$ Th-PH, the An-P bond in other species exhibit multiple bond features. This multiple bond phenomenon also exists in our previous studies of neptunimine $\left(\mathrm{HN}=\mathrm{NpH}_{2}\right)$ and plutonimine $\left(\mathrm{HN}=\mathrm{PuH}_{2}\right){ }^{43}$

Reaction coefficients. In this paper, rate constant calculations are accomplished by KiSThelP software with variational transition state theory (VTST):

$$
k^{\mathrm{GT}}=\sigma \frac{k_{\mathrm{b}} T}{h} \frac{Q^{\mathrm{TS}}(T, s)}{N_{\mathrm{A}} Q^{\mathrm{R}}(T, s)} \exp \left(-\frac{V^{\ddagger}(s)}{k_{\mathrm{b}} T}\right)
$$

The structure and frequency results with the B3LYP/SDD/ aug-cc-pVTZ level is used as the input for the KiSThelP program. It is expected that tunneling effects play an important role in the reaction which involves the transfer of hydrogen

Table 4 Calculated thermal rate constants $\left(\mathrm{s}^{-1}\right)$ for the reaction of $\mathrm{U}+\mathrm{PH}_{3}$ at the B3LYP/SDD/aug-cc-pVTZ level of theory

\begin{tabular}{|c|c|c|c|c|c|c|c|c|c|}
\hline$T \mathrm{~K}$ & \multicolumn{3}{|c|}{$\mathrm{UPH}_{3} \rightarrow \mathrm{TS} 1 \rightarrow \mathrm{HUPH}_{2}$} & \multicolumn{3}{|c|}{$\mathrm{HUPH}_{2} \rightarrow \mathrm{TS} 2 \mathrm{a} \rightarrow \mathrm{H}_{2} \mathrm{UPH}$} & \multicolumn{3}{|c|}{$\mathrm{HUPH}_{2} \rightarrow \mathrm{TS} 2 \mathrm{~b} \rightarrow \mathrm{H}_{2} \mathrm{UPH}$} \\
\hline 300 & $2.14 \times 10^{9}$ & $2.23 \times 10^{9}$ & $3.56 \times 10^{9}$ & $2.43 \times 10^{5}$ & $4.12 \times 10^{5}$ & $3.60 \times 10^{5}$ & $2.53 \times 10^{3}$ & $3.40 \times 10^{3}$ & $3.24 \times 10^{3}$ \\
\hline 350 & $6.34 \times 10^{9}$ & $6.48 \times 10^{9}$ & $9.45 \times 10^{9}$ & $2.14 \times 10^{6}$ & $3.14 \times 10^{6}$ & $2.90 \times 10^{6}$ & $3.77 \times 10^{4}$ & $4.69 \times 10^{4}$ & $4.55 \times 10^{4}$ \\
\hline 400 & $1.45 \times 10^{10}$ & $1.46 \times 10^{10}$ & $2.00 \times 10^{10}$ & $1.09 \times 10^{7}$ & $1.46 \times 10^{7}$ & $1.39 \times 10^{7}$ & $2.81 \times 10^{5}$ & $3.33 \times 10^{5}$ & $3.26 \times 10^{5}$ \\
\hline 550 & $7.33 \times 10^{10}$ & $7.18 \times 10^{10}$ & $8.79 \times 10^{10}$ & $2.46 \times 10^{8}$ & $2.88 \times 10^{8}$ & $2.82 \times 10^{8}$ & $1.25 \times 10^{7}$ & $1.36 \times 10^{7}$ & $1.35 \times 10^{7}$ \\
\hline 600 & $1.06 \times 10^{11}$ & $1.03 \times 10^{11}$ & $1.23 \times 10^{11}$ & $4.95 \times 10^{8}$ & $5.64 \times 10^{8}$ & $5.54 \times 10^{8}$ & $2.87 \times 10^{7}$ & $3.10 \times 10^{7}$ & $3.07 \times 10^{7}$ \\
\hline
\end{tabular}


Table 5 Calculated thermal rate constants for the reaction of $\mathrm{Th}+\mathrm{PH}_{3}$ at the B3LYP/SDD/aug-cc-pVTZ level of theory ${ }^{a}$

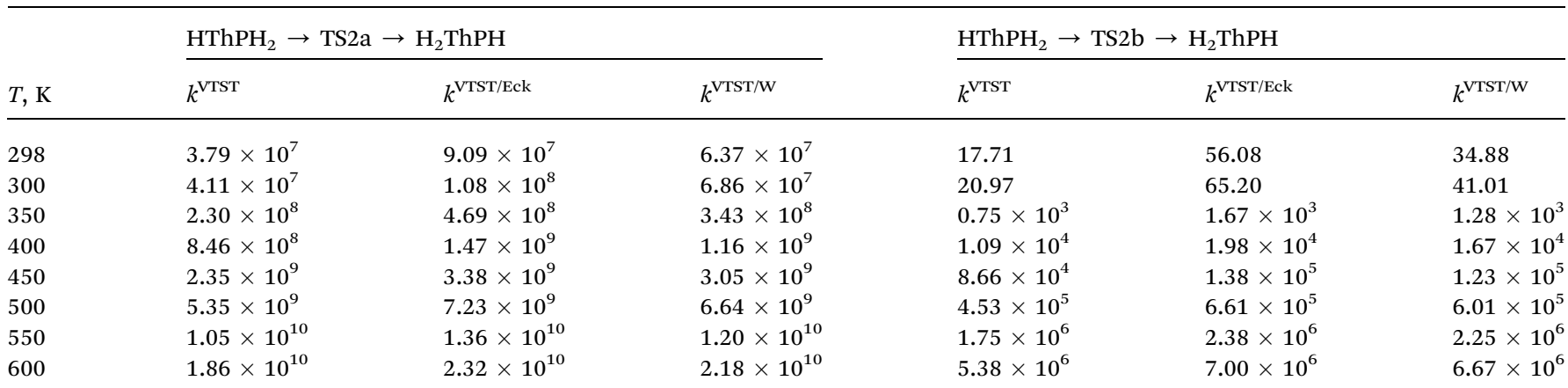

${ }^{a}$ Rate constant in $\mathrm{s}^{-1}$.

atoms. $^{44}$ Therefore, in this study, the one-dimensional tunneling effects by Wigner and Eckart were considered. The rate constants at different temperatures (298 to $600 \mathrm{~K}$ ) are shown in Tables 4 and 5 . The $\log _{10} k$ versus $1000 / T$ plots are incorporated in experimental rate studies and depicted in Fig. 7 and 8 .

From the table we can see that the process of dissociating the first $\mathrm{P}-\mathrm{H}$ bond occur the fastest compared to the other steps. The effect of temperature on the reaction rate is also significant, and as the temperature increases, the reaction proceeds faster, especially when the $\mathrm{P}-\mathrm{H} 2$ bond breaks. We also found that the isomerization channel reacts faster than the dehydrogenation channel at room temperature. For the reaction of $\mathrm{Th}+\mathrm{PH}_{3}$, the dissociating process of the $\mathrm{P}-\mathrm{H} 1$ bond requires two steps, and the energy barrier of the first step is very small $\left(0.06 \mathrm{kcal} \mathrm{mol}^{-1}\right)$, the exact reaction rate value is not obtained by this method. Even so, this process happens very quickly since the energy barrier is very small.
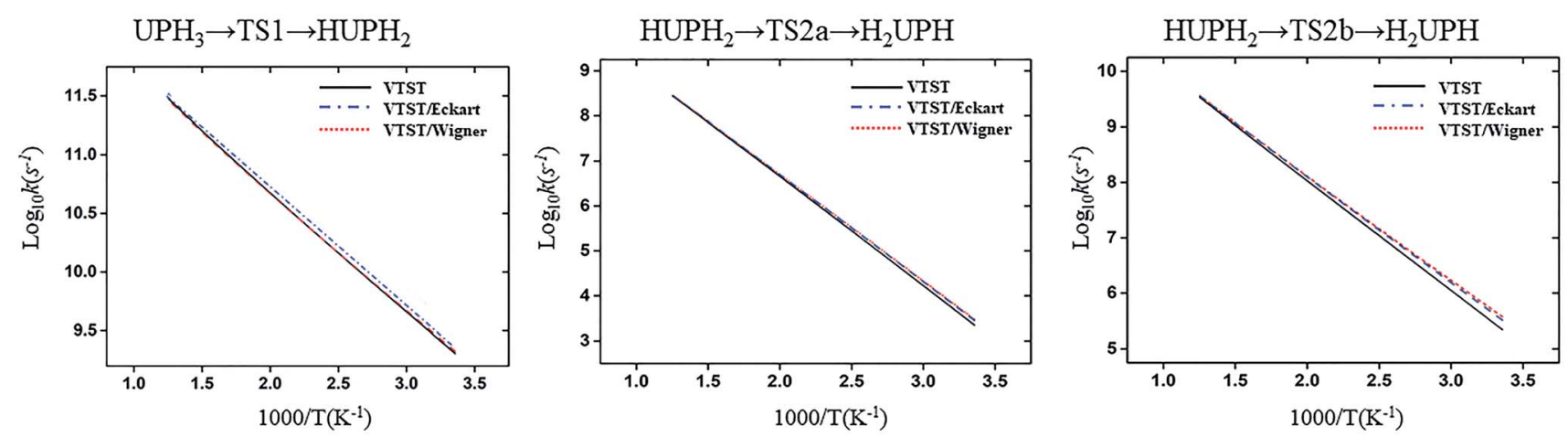

Fig. 7 Computed VTST rate constant and temperature plots of the reaction of $\mathrm{U}+\mathrm{PH}_{3}$ obtained by using B3LYP/SDD/aug-cc-pVTZ energies and frequencies: $\log _{10} k\left(\mathrm{~s}^{-1}\right)$ versus $1000 / T$.
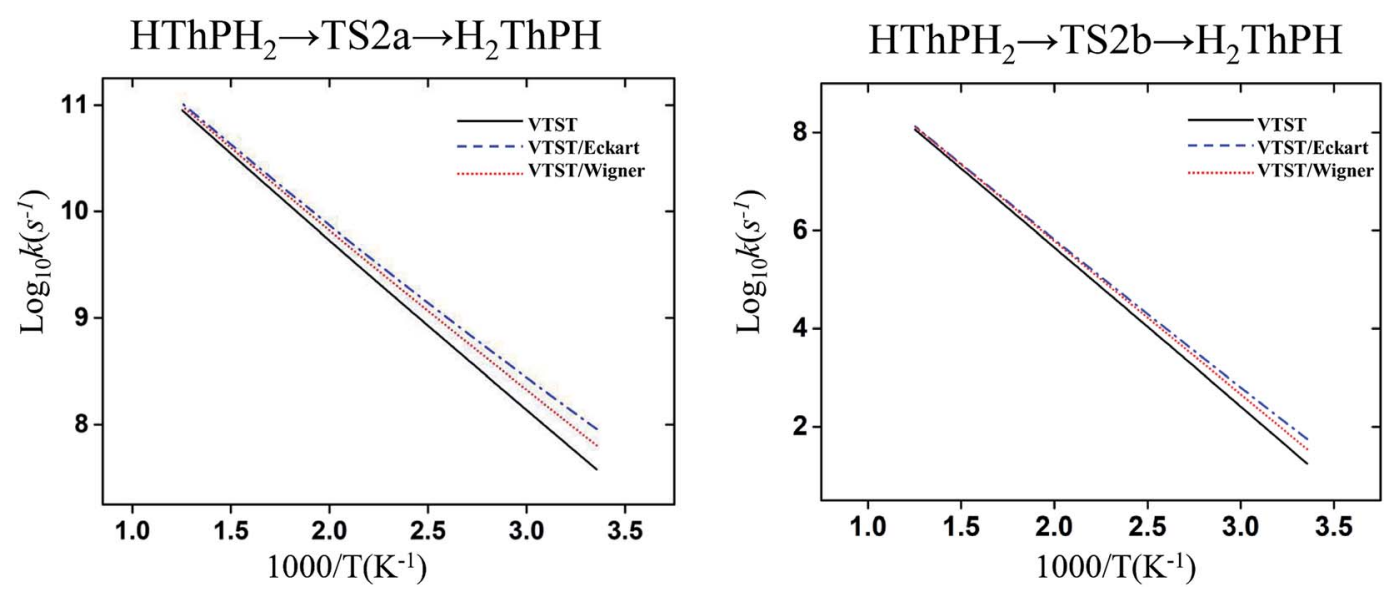

Fig. 8 Computed VTST rate constant and temperature plots of the reaction of Th $+\mathrm{PH}_{3}$ obtained by using B3LYP/SDD/aug-cc-pVTZ energies and frequencies: $\log _{10} k\left(\mathrm{~s}^{-1}\right)$ versus $1000 / T$. 
As for the impact of tunneling effects, it can be seen that the split of the curve at low temperature region are more obvious than that at the high temperature region. This indicates that the tunneling effect is more significant at low temperature region (room temperature), and the reaction rates are faster than expected. Take the $\mathrm{HThPH}_{2} \rightarrow \mathrm{TS} 2 \mathrm{a} \rightarrow \mathrm{H}_{2} \mathrm{ThPH}$ process as an example. The reaction rates considering the tunneling effect are nearly doubled that of the unconsidered. In addition, we found that the tunneling effect is greater for the TS2a than that of other processes. This may due to the TS2a is the isomerization process, since the large-amplitude conformational motions that bring system centers in close proximity can promote this tunneling. ${ }^{\mathbf{4 4}}$

\section{Conclusions}

In conclusion, we discuss the detailed reaction mechanisms of the gas-phase reaction of $\mathrm{U}$ and $\mathrm{Th}$ with $\mathrm{PH}_{3}$. Two types of reaction channels of the $\mathrm{P}-\mathrm{H}$ bond activate by $\mathrm{U}$ and $\mathrm{Th}$ are discussed. Bonding evolution was analyzed by using several methods, including ELF, QTAIM and NBO calculations. The reaction rate constants are predicted by using VTST method with 1D tunneling effect. The main conclusions are summarized as follows. (1) The $\mathrm{U}+\mathrm{PH}_{3}$ and $\mathrm{Th}+\mathrm{PH}_{3}$ have similar reaction mechanisms. The reaction proceeds along two channels of isomerization and dehydrogenation. The difference between the two reactions is that the $\mathrm{U}+\mathrm{PH}_{3}$ reaction needs one step to dissociate the $\mathrm{P}-\mathrm{H} 1$ bond, while the reaction of $\mathrm{Th}+\mathrm{PH}_{3}$ takes two steps. (2) Chemical bond evolution analysis results show that all the bonds involved in the reaction exhibit covalent bond characteristics, and the An-P bond in Th species exhibit more multiple bond properties than U species. (3) Based on the energies and frequencies, the rate constants are obtained by using the VTST method, and the 1D tunneling effect is considered. From the results, we know that as the temperature increases, the reaction rate increases. These results contribute to our growing knowledge of the chemistry of actinides, and establish a theoretical foundation for the study of activation of prototypical bonds by actinides atoms.

\section{Conflicts of interest}

There are no conflicts to declare.

\section{Acknowledgements}

This work is supported by National Natural Science Foundation of China (NSFC) (Grant No. 11604187), the Natural Science Young Foundation of Shanxi Province (Grant No. 201801D221004), the foundation for Outstanding Young Scholars of Shanxi Province, China (Grant No. 201601D021001), the fund for Shanxi "1331 Project" Key Subjects Construction, the Outstanding young academic leader of Shanxi Province, the Cooperation projects of Institute of Applied Physics and Computational Mathematics, and Open Fund of Key Laboratory of Advanced Reactor Engineering and Safety, Ministry of Education (Tsinghua University, China). We are very grateful to
Dr Sobereva for many helpful discussions and providing us with the Multiwfn package. We would like to thank the reviewers for the valuable suggestions on improving our study.

\section{References}

1 T. W. Hayton, Chem. Commun., 2013, 49, 2956-2973.

2 D. S. J. Arney, R. C. Schnabel, B. C. Scott and C. J. Bums, J. Am. Chem. Soc., 1996, 118, 6780-6781.

3 M. Ephritikhine, Coord. Chem. Rev., 2016, 319, 35-62.

4 A. C. Behrle, L. Castro, L. Maron and J. R. Walensky, J. Am. Chem. Soc., 2015, 137, 14846-14849.

5 X. Wang, L. Andrews, M. Knitter, P. A. Maimqvist and B. O. Roos, J. Phys. Chem. A, 2009, 113, 6064-6069.

6 L. Andrews, X. Wang, R. Lindh, B. O. Roos and C. J. Marsden, Angew. Chem., Int. Ed., 2008, 47, 5366-5370.

7 H. G. Cho and L. Andrews, Coord. Chem. Rev., 2017, 335, 76102.

8 X. Wang, L. Andrews and C. Marsden, Chem.-Eur. J., 2008, 14, 9192-9201.

9 X. Wang, L. Andrews and C. Marsden, Chem.-Eur. J., 2007, 13, 5601-5606.

10 L. Andrews, H. G. Cho, K. S. Thanthiriwatte and D. A. Dixon, Inorg. Chem., 2017, 56, 2949-2957.

11 W. Niu, H. Zhang, P. Li and T. Gao, Int. J. Quantum Chem., 2015, 115, 6-18.

12 K. J. de Almeida and A. Cesar, Organometallics, 2006, 25, 3407-3416.

13 E. D. Santo, M. D. C. Michelini and N. Russo, Organometallics, 2009, 28, 3716-3726.

14 P. Li, W. Niu and T. Gao, RSC Adv., 2014, 4, 29806-29817.

15 P. Li, W. Niu, T. Gao and H. Wang, ChemPhysChem, 2015, 15, 3078-3088.

16 A. D. Becke and K. E. Edgecombe, J. Phys. Chem., 1990, 92, 5397-5403.

17 R. F. W. Bader, A quantum theory. A quantum theory, Clarendon, Oxford, 1990, pp. 361-373.

18 I. Mayer, Chem. Phys. Lett., 1985, 97, 270-274.

19 A. E. Reed and F. Weinhold, J. Chem. Phys., 1985, 83, 17361740.

20 A. E. Reed, L. A. Curtiss and F. Weinhold, Chem. Rev., 1988, 88, 899-926.

21 A. Fernandez-Ramos, B. A. Ellingson, B. C. Garrett and D. G. Truhlar, Rev. Comput. Chem., 2007, 23, 125-232.

22 C. Eckart, Phys. Rev., 1930, 35, 1303-1309.

23 E. Wigner, Z. Phys. Chem., 1932, 19, 203-216.

24 M. J. Frisch, G. W. Trucks, H. B. Schlegel, G. E. Scuseria, M. A. Robb, J. R. Cheeseman, G. Scalmani, V. Barone, G. A. Petersson, H. Nakatsuji, X. Li, M. Caricato, A. V. Marenich, J. Bloino, B. G. Janesko, R. Gomperts, B. Mennucci, H. P. Hratchian, J. V. Ortiz, A. F. Izmaylov, J. L. Sonnenberg, D. Williams-Young, F. Ding, F. Lipparini, F. Egidi, J. Goings, B. Peng, A. Petrone, T. Henderson, D. Ranasinghe, V. G. Zakrzewski, J. Gao, N. Rega, G. Zheng, W. Liang, M. Hada, M. Ehara, K. Toyota, R. Fukuda, J. Hasegawa, M. Ishida, T. Nakajima, Y. Honda, O. Kitao, H. Nakai, T. Vreven, K. Throssell, 
J. A. Montgomery Jr, J. E. Peralta, F. Ogliaro, M. J. Bearpark, J. J. Heyd, E. N. Brothers, K. N. Kudin, V. N. Staroverov, T. A. Keith, R. Kobayashi, J. Normand, K. Raghavachari, A. P. Rendell, J. C. Burant, S. S. Iyengar, J. Tomasi, M. Cossi, J. M. Millam, M. Klene, C. Adamo, R. Cammi, J. W. Ochterski, R. L. Martin, K. Morokuma, O. Farkas, J. B. Foresman, and D. J. Fox, Gaussian 16, Revision B.01, Gaussian, Inc, Wallingford CT, 2016.

25 C. Lee, W. Yang and R. G. Parr, Phys. Rev. B: Condens. Matter Mater. Phys., 1988, 37, 785-789.

26 J. P. Perdew, K. Burke and Y. Wang, Phys. Rev. B: Condens. Matter Mater. Phys., 1996, 54, 16533-16539.

27 A. D. Becke, Phys. Rev. A, 1988, 38, 3098-3100.

28 W. Küchle, M. Dolg, H. Stoll and H. Preuss, J. Chem. Phys., 1994, 100, 7535-7542.

29 D. E. Woon and T. H. Dunning, J. Chem. Phys., 1994, 100, 2975-2988.

30 Y. Zhao and D. G. Truhlar, Comput. Theor. Chem., 2008, 120, 215-241.

31 D. A. Pantazis and F. Neese, J. Chem. Theory Comput., 2011, 7, 677-684.

32 D. A. Pantazis, X. Y. Chen, C. R. Landis and F. Neese, J. Chem. Theory Comput., 2008, 4, 908-919.
33 E. van Lenthe, E. J. Baerends and J. G. Snijders, J. Chem. Phys., 1993, 99, 4597-4610.

34 F. Neese, Wiley Interdiscip. Rev.: Comput. Mol. Sci., 2012, 2, 73-78.

35 M. E. Alikhani, M. C. Michelini, N. Russo and B. Silvi, J. Phys. Chem. A, 2008, 112, 12966-12974.

36 D. O. Kashinski, G. M. Chase, R. G. Nelson, O. E. Di. Nallo, A. N. Scales, D. L. Vanderley and E. F. C. Byrd, J. Phys. Chem. A, 2017, 121, 2265-2273.

37 N. M. Kreienborg and C. Merten, Phys. Chem. Chem. Phys., 2019, 21, 3506-3511.

38 G. D. Liberto, R. Conte and M. Ceotto, J. Chem. Phys., 2018, 148, 104302.

39 T. Lu and F. Chen, J. Comput. Chem., 2012, 33, 580-592.

40 S. Canneaux, F. Bohr and E. Henon, J. Comput. Chem., 2013, 35, 82-93.

41 K. M. Smith, R. Poli and J. N. Harvey, New J. Chem., 2000, 24, 77-80.

42 D. Cremer and E. Kraka, Angew. Chem., Int. Ed., 1984, 23, 627-628.

43 P. Li, W. Niu and T. Gao, J. Mol. Model., 2015, 21, 316.

44 R. J. McMahon, Science, 2003, 299, 833. 